\title{
Performance Evaluation of Recycled Asphalt Mixtures Containing Construction and Demolition Waste Applicated as Pavement Base
}

\author{
Le Ding $\mathbb{B}^{D}$, Junhui Zhang $\mathbb{D}^{\mathrm{D}}$, Bowen Feng, and Cheng Li \\ National Engineering Laboratory of Highway Maintenance Technology, Changsha University of Science \& Technology, Changsha, \\ Hunan 410004, China \\ Correspondence should be addressed to Junhui Zhang; zjhseu@csust.edu.cn
}

Received 5 May 2020; Revised 30 June 2020; Accepted 2 July 2020; Published 23 July 2020

Academic Editor: Fan Gu

Copyright $(2020$ Le Ding et al. This is an open access article distributed under the Creative Commons Attribution License, which permits unrestricted use, distribution, and reproduction in any medium, provided the original work is properly cited.

Construction and demolition waste contain large amount of concrete and bricks. To identify its feasibility of applying in asphalt stabilized gravel mixtures as pavement base, this paper carried out researches on properties of recycled asphalt mixture (RAM) by laboratory testing, under different contents of recycled aggregates (RA) and proportions of bricks to concrete. First, the basic physical properties of each component of the RAM were determined. According to the actual screening passing rate, the Bailey method was used to design and verify the grading of RAM, and then initial asphalt content was estimated. The stability, flow value, voidage, and bulk density were obtained by Marshall Test, and the optimal asphalt-aggregate ratios were determined under different RA contents and proportion of bricks to concrete. Subsequently, the uniaxial compression test, splitting tensile test, immersion Marshall test, freeze-thaw splitting test, and Hamburg rutting test were performed to investigate mechanical properties, water stability, and high-temperature stability of RAM. The results shows that as the content of RA increases from $0 \%$ to $100 \%$, the corresponding compressive strength, resilient modulus, and splitting tensile strength all decrease; the same change trend is presented in the residual stability and freeze-thaw splitting test strength ratio and rutting depth. According to the requirement of pavement base of high-grade roads in China's standards, the recommended RA content and proportion of bricks to concrete were proposed for the design RAM.

\section{Introduction}

Extensive urbanization in China has led to the generation of multitudinous construction and demolition wastes (CDW), about 1.7 billion tons in 2019, resulting in many imminent problems to be solved urgently, e.g., occupation of land, overconsumption of resources, and environmental pollution [1-3]. Simultaneously, for the sake of environmental protection, the government has already banned or restricted quarrying in many areas of China, leading to source materials used for highway engineering becoming more costly and difficult to obtain $[4,5]$. Thus, recycling CDW into road materials is a promising way to address these issues, with significant environmental and economical benefits.

The composition of CDW is complicated with many sources; waste concrete and bricks are two main parts occupied for $60 \%$ and $20 \%$ of the whole wastes [6,7], and they can be processed into RA after crushing and screening. Compared with natural aggregates (NA), RA are covered with lots of cement mortar and microcracks. Thus, RA show significant characteristics of low strength, high voidage, small bulk density, and large water absorption [8]. Some studies on the application of CDW have verified its feasibility of using in highway engineering, as pavement base materials [9-12] or subgrade fillers [13]. Their mechanical properties [14-16], durability and stability [17-19], and effect of specimens compaction method were comprehensively studied [20]. To improve the property of these RA mixtures, some kinds of additives were optional [21-23]. To realize the accuracy and efficient utilization of CDW, the separation technology of RA compositions, e.g., recycled concrete aggregates (RCA) and recycled brick aggregates (RBA), developed rapidly. Lots of physical methods, including spirals, density and magnetic eddy current, and 
optical and air jigging, have already achieved effective separation of RCA and RCB [24-26]. However, most existing tests only used waste concrete, and waste bricks were discarded, or the RA were regarded as an integral, and the effect of proportions of internal compositions is often ignored. The impact of recycled concrete and bricks on the performance of RAM has not been investigated deeply when it comes to be used as pavement base materials.

In this paper, the recycled coarse aggregates (4.75 26.5 mm), taken from RCA and RBA, were used for replacing natural ones, for application of RAM as pavement base. The RA content was set in five ratios: $0 \%, 25 \%$, $50 \%, 75 \%$, and $100 \%$, and four proportions of bricks to concrete $(0: 10,2: 8,4: 6,6: 4)$ were considered. First, the adhesions between asphalt and three types of coarse aggregates (NA, RCA, RBA) were investigated from the view of microstructure by scanning electron microscope (SEM). Then the properties of RAM were determined by the Standard Marshall Test, and the optimal asphalt dosage was obtained under different RA contents and brickconcrete proportions. On this basis, the performance tests of RAM applicated as the pavement base, including mechanical properties, temperature stability, and water stability, were carried out to find a suitable design scheme of RAM.

\section{Materials}

\subsection{Asphalt Mixtures Composition}

2.1.1. Coarse and Fine Aggregates. Three types of aggregates were used: RCA, RBA, and NA. RA were supplied by a CDW recycling plant in Changsha, China. After removing impurities (ceramics, wood, rubber, etc), the CDW were screened into RA in four gradings: $0-4.75 \mathrm{~mm}, 4.75-9.5 \mathrm{~mm}$, $9.5-19 \mathrm{~mm}$, and $19-26.5 \mathrm{~mm}$. The particles of size larger than $26.5 \mathrm{~mm}$ were eliminated, and the RCA and RBA were separated manually (Figure 1).

Since it was difficult to identify the ingredients of finer $\mathrm{RA}$, the used aggregates of grading less than $4.75 \mathrm{~mm}$ were all selected from NA. The remaining three gradings' aggregates were composed of NA and RA in proportion. The properties of RA and NA are evaluated in Table 1 according to China's standard: Aggregate Test Code for Highway Engineering (JTG E42-2005). It is indicated that the RA had a lower apparent density, a higher water absorption, and needle flake content. The main reason is the change of performances ascribes to the adsorbed mortar on the surface of RA.

2.1.2. Asphalt and Mineral Powder. The engineering properties of asphalt binder are presented in Table 2. All of them complied with the requirements of Highway Asphalt Pavement Construction Technical Specifications (JTG F402004). The mineral powder was obtained from a commercial source, its specific gravity was equal to $2.728 \mathrm{~g} / \mathrm{cm}^{3}(>2.5)$, and the hydrophilic coefficient was $0.79(<1)$, which also could meet the requirement of JTG F40-2004.
2.1.3. Grading Design. The aggregate grading design has a great impaction on the mechanical properties, an excellent grade is a necessary precondition to ensure the service life of the asphalt pavement layer [27]. In this test, to form continuous graded skeleton with dense structure with large particle size and less asphalt content, ATB-25 was selected as the targeted grading for its high shear and flexural tensile strength. Since Bailey method is effective in making coarse aggregates to form a dense skeleton, this method is used to carry out grading design [28]. The synthetic Bailey grading curve is shown in Figure 2. It is close to the recommended median curve of ATB-25 in China's standard: Aggregate Test Specification of Highway Engineering (JTG E42-2005). The coarse RA mainly replaces NA in the same grading. Since the finer RA were hardly to be distinguished as concrete or bricks, the synthetic prorotion of bricks to concrete in RAM would be uncontrollable in the conditon of adding finer RA. On this basis, the detailed dosage RCA and RBA were selected in accordance with given proportions in each grading of aggregates, and the specified RA contents and proportion of bricks to concrete can be realized simultaneously.

\subsubsection{Determination of Optimal Asphalt Content.} Marshall testing was used to obtain the optimal asphaltaggregate ratio. First, the synthetical bulk specific gravity $\gamma_{\mathrm{sb}}$ and the estimated optimal asphalt-aggregate ratio $P_{\mathrm{a}}$ were calculated; see equations (1) and (2). Then the asphalt-aggregate ratio was changed gradually with an increase of $0.3 \% \sim 0.5 \%$, to identify the optimal one by comparative analysis in the property of RAM.

$$
\begin{aligned}
\gamma_{\mathrm{sb}} & =\frac{100}{\left(P_{1} / \gamma_{1}\right)+\left(P_{2} / \gamma_{2}\right)+\cdots+\left(P_{n} / \gamma_{n}\right)}, \\
P_{\mathrm{a}} & =\frac{P_{\mathrm{a} 1} \times P_{\mathrm{sb} 1}}{\gamma_{\mathrm{sb}}},
\end{aligned}
$$

where $P_{1}, P_{2}, \ldots, P_{n}$ is the mixture ratio of different mineral material components; $\gamma_{1}, \gamma_{2}, \ldots, \gamma_{n}$ is the the bulk specific gravity of the corresponding mineral; $P_{\mathrm{a}}$ is the estimated optimum asphalt-aggregate ratio; $P_{\mathrm{al}}$ is the standard optimum asphalt-aggregate ratio of asphalt mixtures for similar projects; and $P_{\mathrm{sb} 1}$ is the bulk specific gravity of similar engineered aggregates.

The $P_{\mathrm{a}}$ is about $3.8 \%$ by calculation. The content of coarse aggregates was more in RAM than those in common asphalt mixture, and their particle size was big, leading to less asphalt content needed in RAM. The selected testing asphaltaggregate ratios were set as $3.5 \%$ to $4.7 \%$ with an interval of $0.3 \%$. To ensure the accuracy and validity of test results, the test temperature needs to be controlled strictly. The RCA were first put into an oven to be heated to $150^{\circ} \mathrm{C}$, and then poured into a mixing pot for stirring for 180 seconds with the A70 matrix asphalt. And the compaction temperature was controlled in $140^{\circ} \mathrm{C}$. In the mixing process, the proportion of bricks to concrete were set in four cases: $0: 10,2$ : $8,4: 6$, and $6: 4$. It was found that the uniformity of asphalt adhesion on the surface of RA differed a lot. With the increase of the content of RBA, the amount of asphalt absorbed 


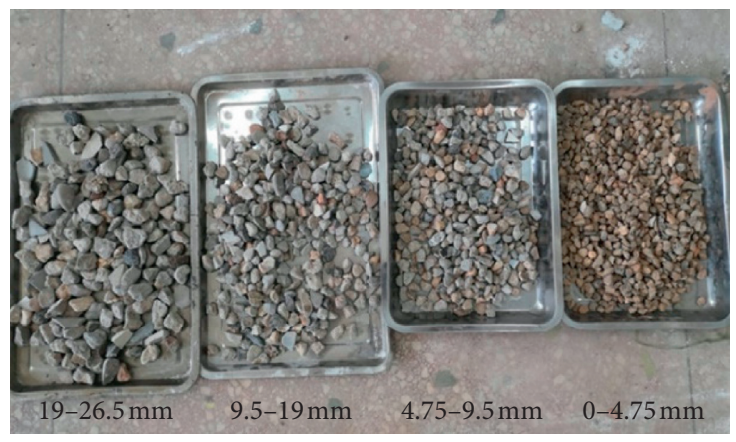

(a)

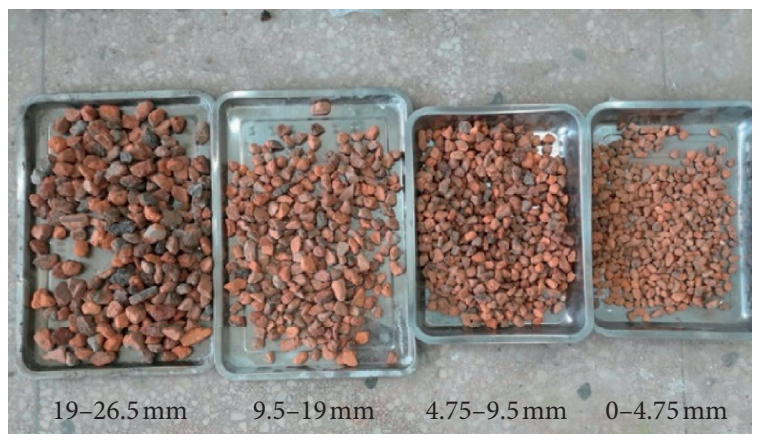

(b)

Figure 1: Source materials. (a) RCA. (b) RBA.

TABLE 1: Characterisation of aggregates.

\begin{tabular}{lccccccccccc}
\hline \multirow{2}{*}{ Detection indexes } & \multicolumn{3}{c}{ RCA $(\mathrm{mm})$} & \multicolumn{3}{c}{ RBA $(\mathrm{mm})$} & \multicolumn{3}{c}{ Limestone natural aggregates } \\
& $4.75-9.5$ & $9.5-19$ & $19-26.5$ & $4.75-9.5$ & $9.5-19$ & $19-26.5$ & $0-4.75$ & $4.75-9.5$ & $9.5-19$ & $19-26.5$ & Code value \\
\hline Apparent density $\left(\mathrm{kg} / \mathrm{m}^{3}\right)$ & 2.50 & 2.55 & 2.53 & 2.38 & 2.41 & 2.44 & 2.723 & 2.721 & 2.713 & 2.711 & $\geq 2.50$ \\
Water absorption (\%) & 5.71 & 5.44 & 5.50 & 17.08 & 16.55 & 14.61 & 0.78 & 0.61 & 0.52 & 0.34 & $\leq 3.0$ \\
Needle flake content (\%) & 7.8 & 7.1 & 3.2 & 7.3 & 6.9 & 3.5 & 12.6 & 8.3 & 9.8 & 6.9 & $\leq 18$ \\
Crushed value (\%) & 26.1 & 26.6 & 27.3 & 28.6 & 29.3 & 29.8 & - & 21.6 & 22.3 & 22.5 & $\leq 28$ \\
\hline
\end{tabular}

TABLe 2: Asphalt property test results and standard value.

\begin{tabular}{ccccc}
\hline Test item & & Test value & Test methods & Specification of JTG F40-2004 \\
\hline \multirow{4}{*}{ Ductility } & Penetration $(\%)$ & 68.5 & T0604-2011 & $60 \sim 80$ \\
& $\left(10^{\circ} \mathrm{C}, 5 \mathrm{~cm} / \mathrm{min}\right), \mathrm{cm}$ & 19 & T0605-2011 & $\geq 15$ \\
& $\left(15^{\circ} \mathrm{C}, 5 \mathrm{~cm} / \mathrm{min}\right), \mathrm{cm}$ & 101 & T0605-2011 & $\geq 100$ \\
& Softening point, ${ }^{\circ} \mathrm{C}$ & 48.3 & T0606-2011 & $\geq 46$ \\
& Flash points, ${ }^{\circ} \mathrm{C}$ & 280 & T0611-2011 & $\geq 260$ \\
& Paraffin content, $\%$ & 2.1 & T0615-2011 & $\leq 2.2$ \\
\hline
\end{tabular}

Test methods referenced from China's Standard Test Methods of Bitumen and Bituminous Mixtures for Highway Engineering (JTG E20-2011).

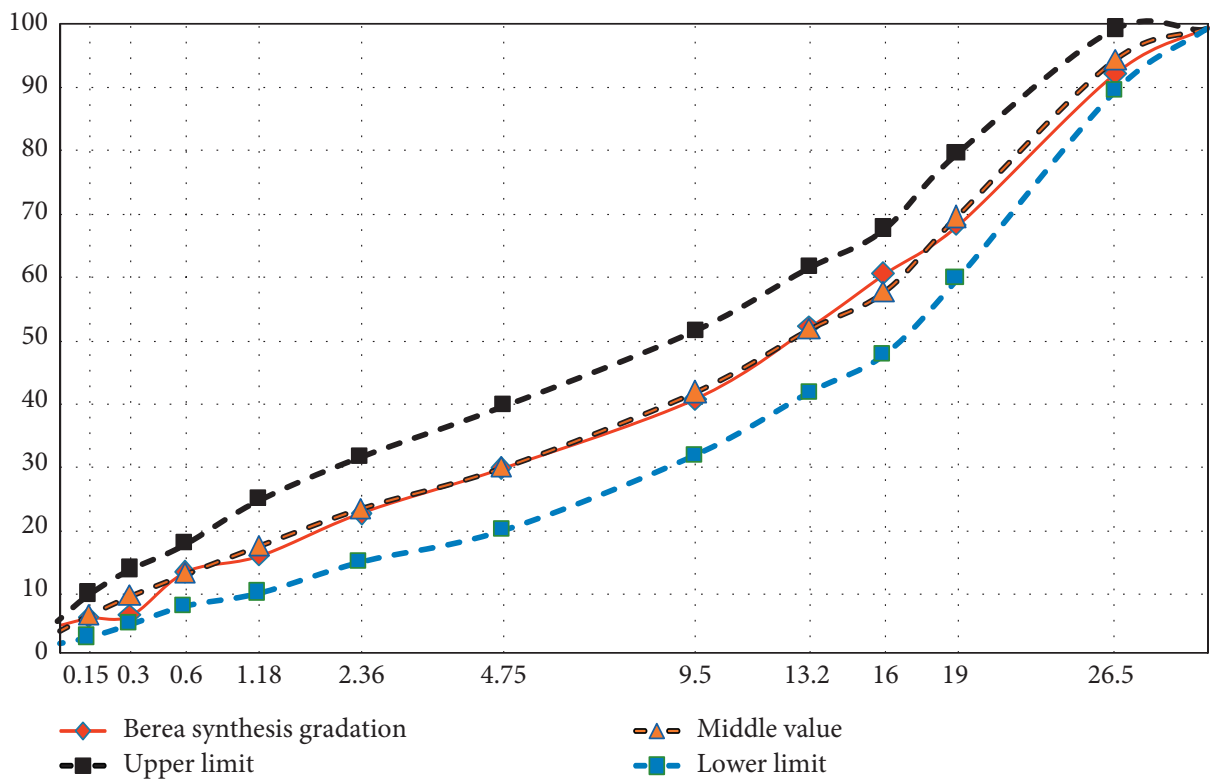

Figure 2: Design grading curve of processed RA. 
on the surface of RA decreases, which proves that the oil absorption rate of RBA is relatively higher than that of RCA. When the RA content is $25 \%$, the uniformity of adsorbed asphalt varies with the changing RBA content; see Figure 3.

In the forming process of tested samples of RAM, the specimens were set as the standard size: $101.6 \times 63.5 \mathrm{~mm}$ (diameter $\times$ height), after compacting for 75 cycles both side, they were cooled for 12 hours at room temperature. Finally, all specimens were stripped ready to undergo Marshell testing. The mass of specimens in water and air and surface dry mass were tested, respectively, then the stability and flow value were tested by Marshall Stability Meter. According to the requirements of the specification (JTG F40-2004), the optimum asphalt-aggregate ratio $\mathrm{OAC}_{\text {opt }}$ can be calculated as equations (3)-(5). In condition of heavy traffic volume and summer hot area, the technical standard for ATB-25 is shown in Table 3.

$$
\begin{aligned}
\mathrm{OAC}_{1} & =\frac{a_{1}+a_{2}+a_{3}+a_{4}}{4}, \\
\mathrm{OAC}_{2} & =\frac{\mathrm{OAC}_{\text {min }}+\mathrm{OAC}_{\text {max }}}{2} \\
\mathrm{OAC}_{\mathrm{opt}} & =\frac{\mathrm{OAC}_{1}+\mathrm{OAC}_{2}}{2}
\end{aligned}
$$

where $a_{1}$ is the asphalt-aggregate ratio of maximum bulk specific gravity; $a_{2}$ is the asphalt-aggregate ratio of maximum stability; $a_{3}$ is the asphalt-aggregate ratio corresponding to the median of the voidage range; $a_{4}$ is the asphalt-aggregate ratio corresponding to the median of the effective asphalt saturation range; $\mathrm{OAC}_{\min }$ is the minimum asphalt-aggregate ratio in accordance with the technical standard of asphalt mixture, $3.5 \%$; $\mathrm{OAC}_{\max }$ is the maximum asphalt-aggregate ratio in accordance with the technical standard of asphalt mixture, $3.8 \%$.

Figure 4 shows the test results of the case of $25 \%$ RA content. It can be found that with the increase of recycled bricks, the properties of RAM present a similar change trend. For instance, when not adding recycled bricks, the $\mathrm{OAC}_{\mathrm{opt}}$ is calculated to be $3.76 \%$, within the range of $\mathrm{OAC}_{\min }-\mathrm{OAC}_{\max }$. For the $\mathrm{OAC}_{\mathrm{opt}}$ in other three cases, proportions of bricks to concrete $(2: 8,4: 6,6: 4)$ were calculated by the same method: $3.77 \%, 3.8 \%, 3.84 \%$. It is worth noting that the flow value of RBA : RCA $(0: 10)$ shows its particular monotonically increasing characteristic. The possible reason is that in the condition of no recycled bricks, with the increase of asphalt dosage, the recycles mixtures contain more fluidity asphalt and less asphalt absorbed on the particle surface [29]; thus, the compression deformation of the specimen becomes larger, and it is seen that the flow value gradually increases. When adding recycled bricks, the change of flow value should comprehensively consider the effect of RBA and RCA.

Identically, the $\mathrm{OAC}_{\text {opt }}$ of RAM in different RA contents is shown in Figure 5. It can be seen that, with the increase of RA content and proportion of bricks to concrete, the $\mathrm{OAC}_{\mathrm{opt}}$ gradually increases. When the proportion of brick to concrete is $6: 4$, as the RA content increases from $0 \%$ to $100 \%$, the $\mathrm{OAC}_{\text {opt }}$ increases by $0.85 \%$. In the condition of $25 \% \mathrm{RA}$ content, with the increase of the proportion of bricks to concrete from $0: 10$ to $6: 4$, the $\mathrm{OAC}_{\text {opt }}$ increases by $0.08 \%$. By the same analysis, when the RA content increases to $50 \%$, $75 \%$, and $100 \%$, the $\mathrm{OAC}_{\text {opt }}$ increases by $0.1 \%, 0.12 \%$, and $0.08 \%$. Therefore, contrasted with proportion of bricks to concrete, the RA content has a greater impaction on $\mathrm{OAC}_{\mathrm{opt}}$ of RAM.

\subsection{Test Methods}

2.2.1. Microstructure Analysis. To compare the adhesion mechanism between NA, RCA, RBA, and asphalt, it is necessary to analyze their microstructures. The tested aggregates of appropriate particle size were taken out from the internal structure of the specimen artificially, and they were cut into samples of nail size by a precision cutting machine; thus, the microstructure can be observed by SEM. Marshall specimens were prepared with 50\% RA content and proportion of bricks to concrete $4: 6$, the $\mathrm{OAC}_{\text {opt }}$ was $4.14 \%$.

2.2.2. Mechanical Properties. Mechanical strength of RAM mainly depends on the particle friction, aggregate lithology, and performances of the asphalt. Thus, different gradation design and composition of aggregates affect mechanical properties of RAM obviously [30, 31]. The main indexes are compressive strength, resilient modulus, and splitting tensile strength.

When the compressive strength and resilient modulus were measured, the specimens were formed by static pressing with a load of $2000 \mathrm{kN}$. The height and diameter of the specimens were both $100 \pm 2 \mathrm{~mm}$, and their densities met the requirements of Marshall Standard Compaction. After curing, specimens were subjected to uniaxial compression test with Mechanical Testing System (MTS) at room temperature with a loading rate of $2 \mathrm{~mm} / \mathrm{min}$.

According to the failure load $P$, the loading and unloading tests were carried out step by step in strict accordance with five grading loads: $0.1 P, 0.2 P, 0.3 P, 0.4 P$, and 0.5P. After testing, the compressive strength and elastic modulus were calculated as shown in equations (6) and (7):

$$
R_{\mathrm{C}}=\frac{4 P}{\pi d^{2}}
$$

where $R_{\mathrm{C}}$ is the compressive strength $(\mathrm{MPa})$ of the specimen; $P$ is the maximum load $(\mathrm{N})$ of the specimen at failure limit; and $d$ is the specimen diameter $(\mathrm{mm})$.

$$
E=\frac{P_{5} h}{A \Delta_{5}},
$$

where $P_{5}$ is the fifth load value (MPa); $h$ is the specimen height ( $\mathrm{mm}) ; A$ is the radial cross-sectional area of specimen $(\mathrm{mm})$; and $\Delta_{5}$ is the axial average amplitude fifth loading (mm).

In the splitting tensile strength test, the Standard Marshall Compaction specimens were used, and both sides of them were compacted for 75 cycles. After demoulding, they were placed in a constant temperature tank and 


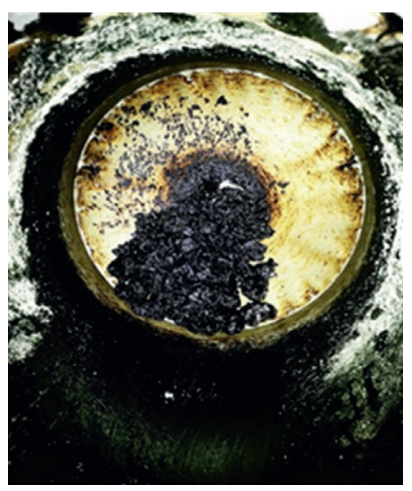

(a)

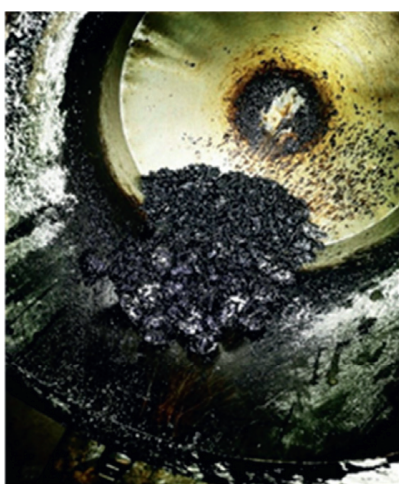

(b)

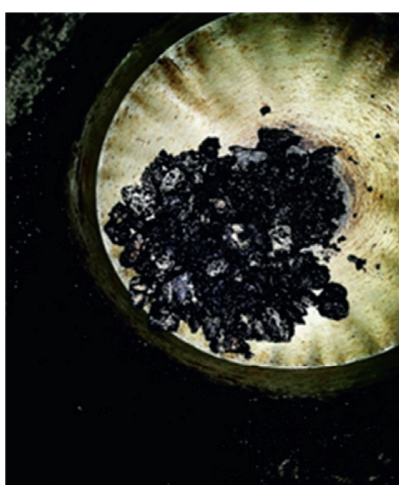

(c)

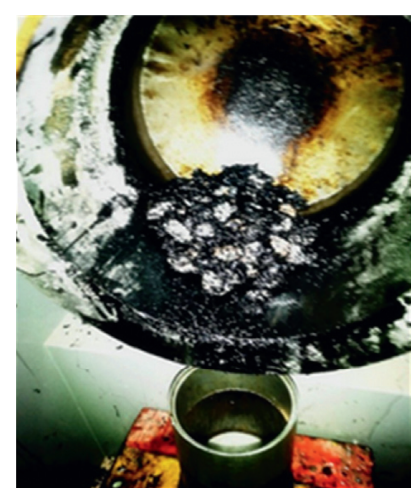

(d)

FiguRE 3: The RAM of different proportions of bricks to concrete. (a) RBA : RCA $=0: 10$. (b) RBA $:$ RCA $=2: 8$. (c) RBA $:$ RCA $=4: 6$. (d) RBA : RCA $=6: 4$.

TABLE 3: Technical requirements for dense gradation base (ATB-25) asphalt mixture.

\begin{tabular}{lc}
\hline Iterm & Technical requirements \\
\hline Nominal maximum size of aggregate & $26.5 \mathrm{~mm}$ \\
Marshall specimen size & $101.6 \mathrm{~mm} \times 63.5 \mathrm{~mm}$ \\
Number of Marshall specimen & 75 cycles double sided \\
compaction & $2-6 \%$ \\
Voidage & $55-70 \%$ \\
Asphalt saturation & $\geq 8 \mathrm{kN}$ \\
Marshall stability & $1.5-4 \mathrm{~mm}$ \\
Flow value & $10-14 \%$ \\
Minimum voids of mineral aggregate & $\geq 1000$ times $/ \mathrm{mm}$ \\
Dynamic stability & $\geq 75 \%$ \\
Freeze-thaw split intensity ratio & $\geq 80 \%$ \\
Residual stability &
\end{tabular}

immersed in water for $1.5 \mathrm{~h}$. The distance of each specimen was $15 \mathrm{~mm}$, the Marshall Stability Meter was used to measure the splitting tensile strength with the loading rate of $50 \mathrm{~mm} / \mathrm{min}$.

2.2.3. Water Stability. The residual stabilities of the two groups of specimens formed by Marshall Compaction were used to evaluate their water stabilities. The size of specimens was $101.6 \times 63.5 \mathrm{~mm}$ (diameter $\times$ height), satisfied with the requirements of China's standard (JTG E20-2011): Standard Test Methods of Bitumen and Bituminous Mixtures for Highway Engineering. Before testing, two groups of specimens were immersed in a $60^{\circ} \mathrm{C}$ constant temperature tank for $30 \mathrm{~min}$ and $48 \mathrm{~h}$, respectively, shown in equation (8).

$$
\mathrm{MS}_{0}=\frac{\mathrm{MS}_{2}}{\mathrm{MS}_{1}} \times 100,
$$

where $\mathrm{MS}_{0}$ is the immersion residual stability $(\mathrm{kN}) ; \mathrm{MS}_{2}$ is the stability of the specimen after soaking for $48 \mathrm{~h}(\mathrm{kN})$; and $\mathrm{MS}_{1}$ is the stability of the specimen after immersion of $0.5 \mathrm{~h}$ $(\mathrm{kN})$.

In the freeze-thaw splitting test, the two groups of Marshall Specimens were processed with compaction for 50 cycles both side. The first group specimens were placed at room temperature, while the second were saturated in a vacuum for $15 \mathrm{~min}$, and then placed in water for $30 \mathrm{~min}$ before taking out. Before sealing them with plastin warps, adding $10 \mathrm{ml}$ water. Subsequently, they were put into a constant temperature and humidity box. One freeze-thaw cycle was completed at this moment. Finally, group 1 and group 2 were put into a $25^{\circ} \mathrm{C}$ constant temperature tank for $2 \mathrm{~h}$, and the maximum failure load was measured to calculate the freeze-thaw splitting test strength ratio:

$$
\mathrm{TSR}=\frac{\mathrm{RT}_{2}}{\mathrm{RT}_{1}} \times 100,
$$

where TSR is the freeze-thaw splitting tensile strength ratio; $\mathrm{RT}_{2}$ is the splitting tensile strength of effective specimens after freeze-thaw cycle ( $\mathrm{MPa})$; and $\mathrm{RT}_{1}$ is the splitting tensile strength of effective specimens with freeze-thaw cycle $(\mathrm{MPa})$.

2.2.4. High-Temperature Stability. To study the impact of brick and concrete aggregates on the high-temperature performance of RAM, the Hamburg rutting test was carried out. The rutting specimens were made in size of $300 \times 300 \times 50 \mathrm{~mm}$ (length/width/thickness) according to China's standard (JTG E20-2011). After being repeatedly rolled by a hydraulic molding machine for 12 cycles, they were placed in the temperature of $45^{\circ} \mathrm{C}$ for $48 \mathrm{~h}$. This condition can simulate the dry state of pavement materials within $5 \sim 12 \mathrm{~h}$. Simultaneously, the comparative tests were conducted in the temperature of $60^{\circ} \mathrm{C}$.

\section{Results and Discussion}

3.1. Microstructure. From the perspective of aggregate surface, RA, especially RCA is formed in cement hydration products, including ettringite, and calcium superoxide, these components have a certain activity to trigger chemical reactions with acid asphalt [32]. Furthermore, the surface of RCA formed rich edges and corners during the crushing process, and they were covered with a large amount of cement mortar, making the surface of RA rougher than NA. Thus, the adhesion between RA and asphalt demonstrated a unique behaviour. The comparison in Figures 6(a) and 6(b) 


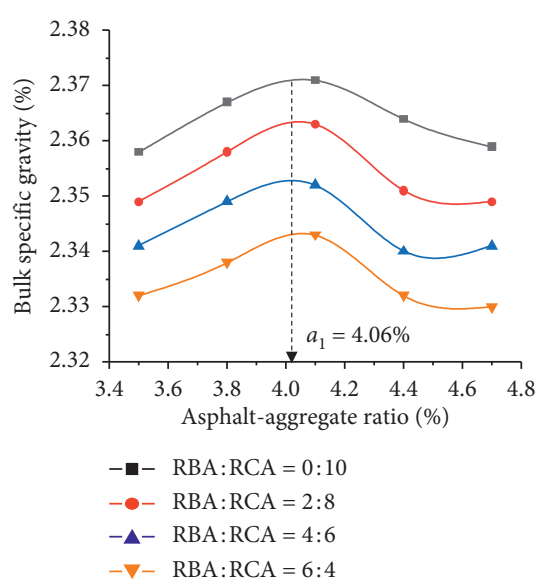

(a)

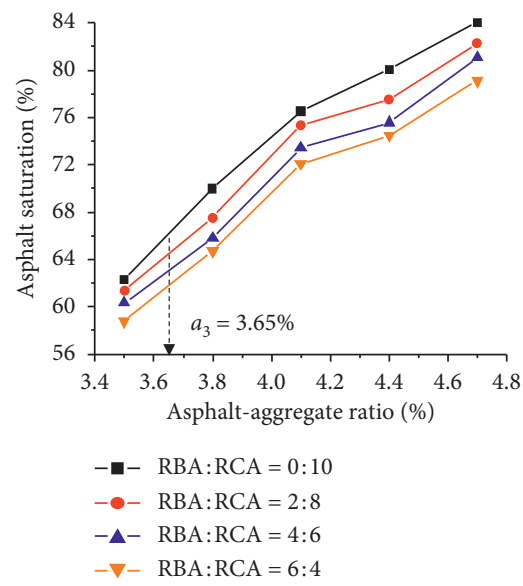

(d)

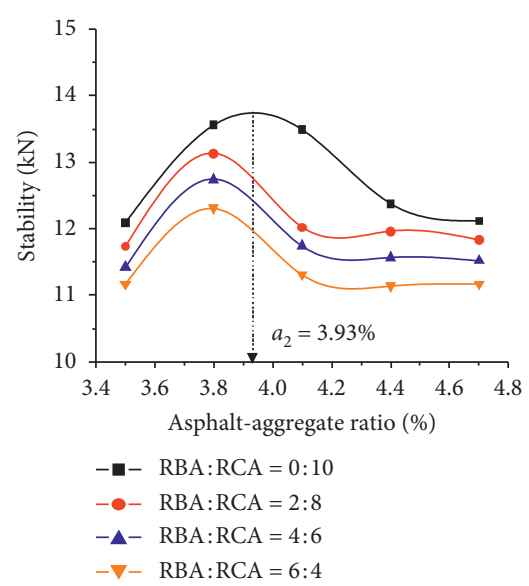

(b)

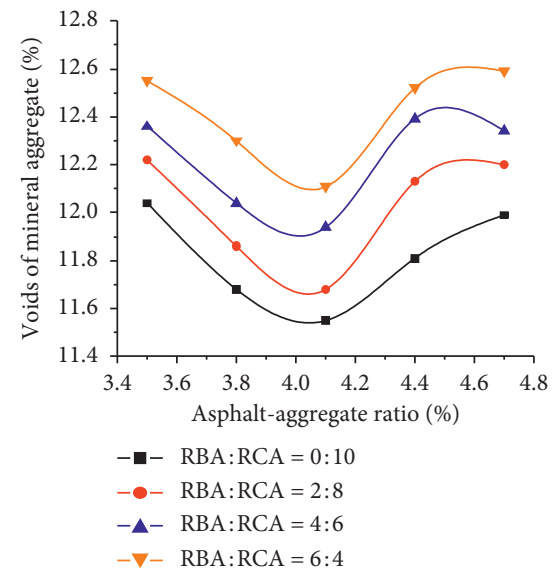

(e)

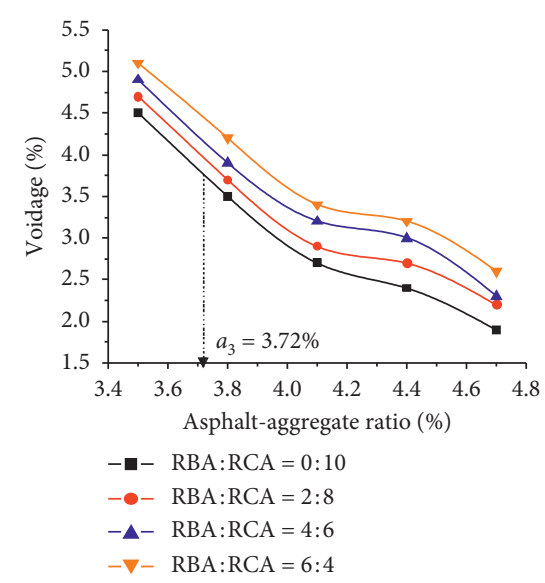

(c)

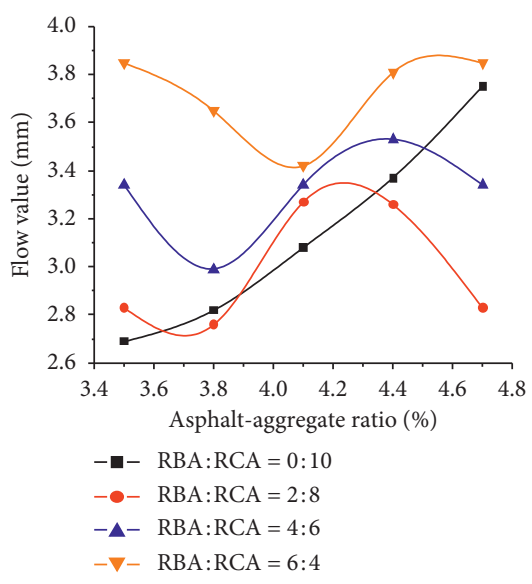

(f)

Figure 4: Marshall test results of asphalt mixtures with 25\% RCA.

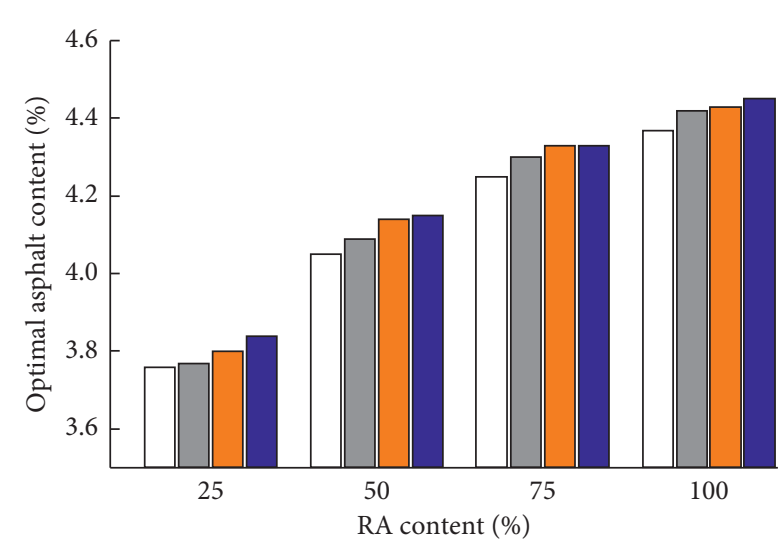

Propotion of brick and concrete

$\begin{array}{ll}\square: 10 & 2: 8 \\ \square: 6 & \\ & 6: 4\end{array}$

FIgURE 5: Optimum asphalt-aggregate ratio in different RCA content.

confirms this phenomenon. The loose structure of mortar and large number of gaps lead to the increase of crushing value of RCA, which indirectly leads to the change of aggregate particle sizes [33]. In contrast, the surface of RBA is smooth with many holes, resulting in higher water absorption and smaller density than RCA, as shown in Figure 6(c). Thus, in the pavement base construction, the RBA content should be controlled within a certain range due to its lower strength $[34,35]$.

The interfaces of three aggregates and asphalt differed significantly. NA and asphalt were bonded with a clear dividing line in good adhesion shown in Figure 6(a). The possible reason is that the selected NA is limestone, an alkaline active substance that can react with acidic materials in asphalt [36]. By contrast, the adhesion interface between RBA and asphalt presented a concave and convex shape; see Figure 6(b). As cement mortar is covered on the surface of RCA, its main chemical components are plentiful $\mathrm{SiO}_{2}$ [37], resulting in a weak reaction with asphalt in a small adhesion. In Figure 6(c), cracks appeared at the adhesion interface between RBA and asphalt, with a comparatively poor adhesion. A large number of microholes appear on the surface of RBA over time, which is advantageous to the physics conglutination of the asphalt, but on the chemical composition analysis, the surface of RBA contains a large amount of $\mathrm{SiO}_{2}$ and $\mathrm{Al}_{2} \mathrm{O}_{3}$ with a stronger acid performance [38], it is 


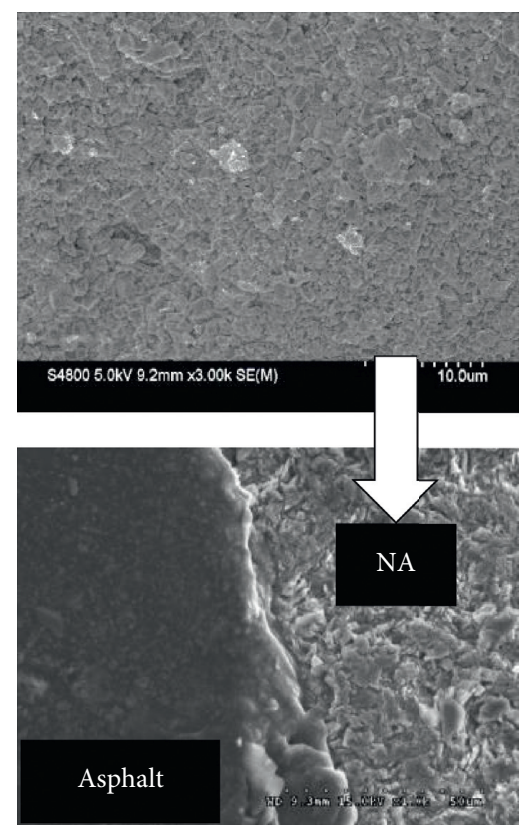

(a)

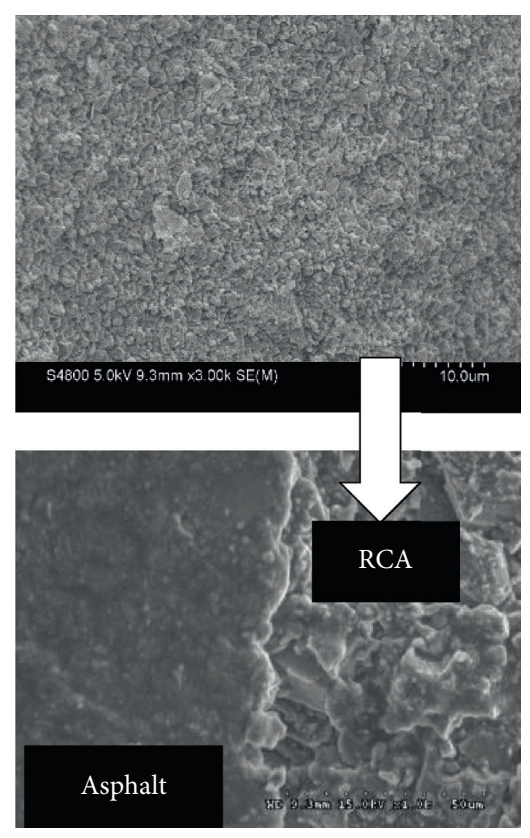

(b)

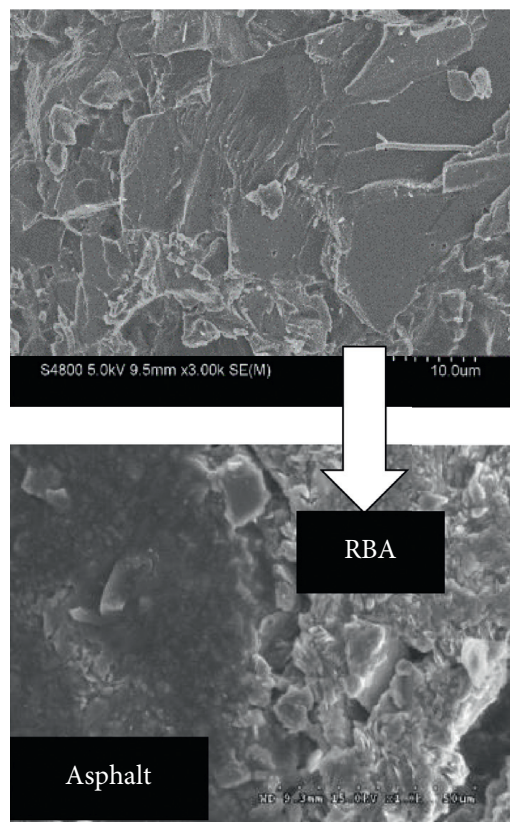

(c)

FIGURE 6: Scanning electron microscope results of three kinds of asphalt mixtures.

difficult to react with asphalt to form strength bonding layers. Therefore, the adherence interface between RBA and asphalt is not neat.

3.2. Mechanical Property. Figure 7(a) shows the change of the compressive strength of RAM under different RA contents. When not adding RBA, and the RA content increased from $0 \%$ to $100 \%$, the compressive strength reduced by $14.4 \%$. When the proportion of brick to concrete was $2: 8$, $4: 6,6: 4$, the compressive strength decreased by $22.7 \%$, $40.5 \%$, and $50.5 \%$, respectively. It shows that with the increasing of proportion of RBA, it adversely affects the compressive strength of RAM. The rank of the strength in three aggregates is NA $>$ RCA $>$ RBA. When the RA content increases, especially when the RBA content increases, the compressive strength of RAM decreases significantly.

For resilient modulus presented in Figure 7(b), when not adding RBA, the resilient modulus decreased by $20.9 \%$ as the RA content changed from $0 \%$ to $100 \%$. In the same condition, when the proportion of bricks to concrete changed to $6: 4$, the resilient modulus decreased by $79.1 \%$, and the reduced amplitude is 3.78 times that of the previous one. The main reason is that the increase in proportion of bricks and concrete leads to a larger voidage and a smaller adhesion for RAM, making resilient modulus of RAM gradually decrease.

Similarly, shown in Figure 7(c), compared to NA, the splitting tensile strength of pure RCA mixtures (100\% of RA content, proportion of bricks to concrete $0: 10$ ) reduced by $21.6 \%$. When not adding NA, and the proportion of bricks to concrete increased to $2: 8,4: 6$, and $6: 4$, the split tensile strength decreased by $37.1 \%, 46.4 \%$, and $48.5 \%$, respectively. Compared with NA, the adhesion of RA to asphalt is weak, with the increase of RA content, the splitting tensile strength of RAM decreases. Particularly, when the proportion of bricks to concrete was $6: 4$ with RA content of $75 \%$ or $100 \%$, the reduced amplitude was significant. In practical construction, considering the variation of tensile strength should be kept within a certain range, when the RA content is greater than $75 \%$, it is recommended the proportion of bricks to concrete should not exceed $4: 6$, to prevent a significant reduction in splitting tensile strength.

3.3. Water Stability. In Figure 8(a), the change law of water stability was consistent with that of the mechanical property. When the increase of proportion of brick to concrete and RA content from $0 \%$ to $100 \%$, the residual stability decreased. The residual stability of pure RCA mixtures decreased by $4.9 \%$ compared to NA. When the proportion of brick to concrete was $6: 4$, with the RA content increase from $0 \%$ to $100 \%$, the residual stability decreased by $13 \%, 2.7$ times of the previous condition, indicating that the proportion of bricks to concrete has a great influence on residual stability. Simultaneously, to meet the specification requirements, the proportions of bricks to concrete should be within $4: 6$ and $2: 8$ in the condition of RA content of $75 \%$ and $100 \%$, respectively.

Figure 8(b) shows the experimental results of freezethaw splitting test strength ratio of RAM. When the RA content exceeded $50 \%$, its decline speed became larger with the increase of proportion of bricks to concrete. In particular, the strength ratio of pure RCA mixtures decreased by $8.5 \%$ compared to NA mixtures. When the proportion of bricks to concrete changed to $6: 4$, this value even decreased by $30.9 \%$. In the specification of China (JTG F40-2004), the requirement of strength ratio of freezing-thawing splitting test should not be less than $75 \%$; thus, the proportion of 


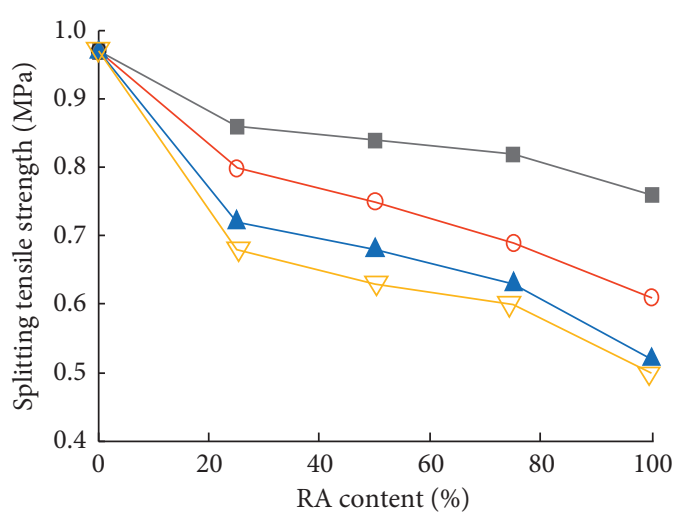

Proportion of brick to concrete

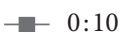

$\frown 2: 8$

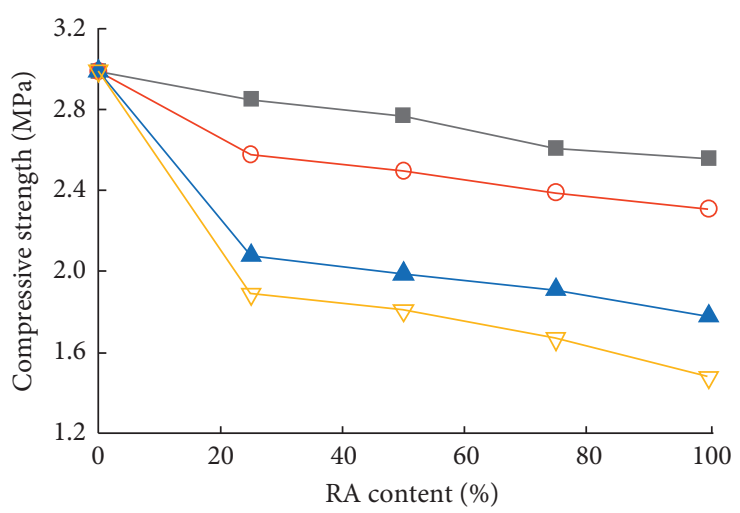

Proportion of brick to concrete

$-4: 6$

$2: 8$

$\nabla$ 6:4

(a)

(b)

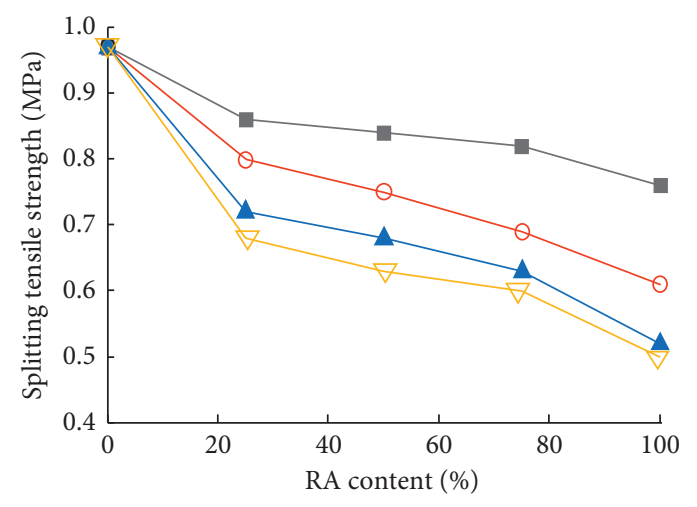

Proportion of brick to concrete

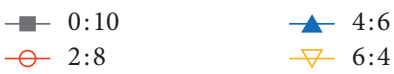

(c)

FiguRE 7: Mechanical test results of recycled asphalt mixtures. (a) Compressive strength. (b) Resilient modulus. (c) Splitting tensile strength.

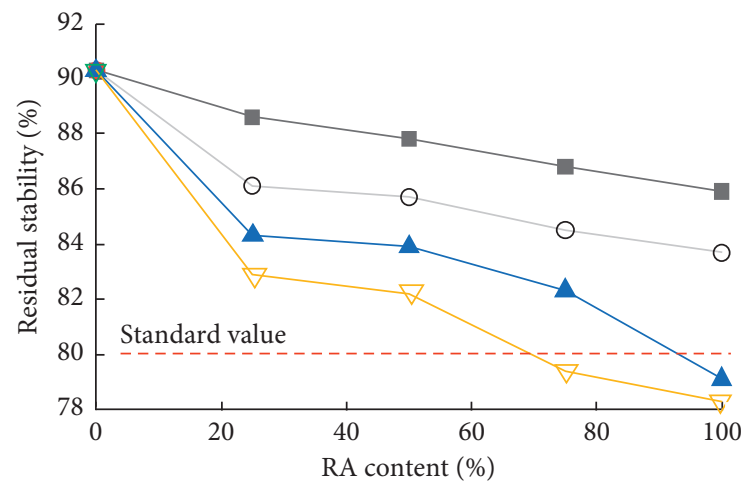

Proportion of brick to concrete

$$
\begin{aligned}
& -0: 10 \\
& -0 \quad 2: 8
\end{aligned}
$$

(a)

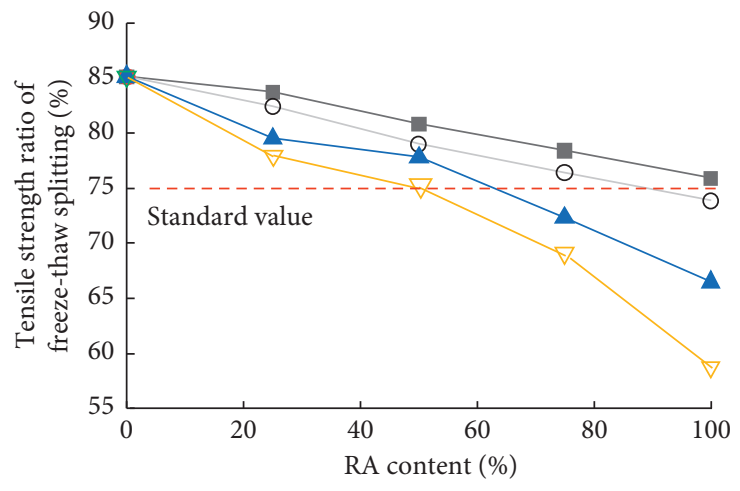

Proportion of brick to concrete

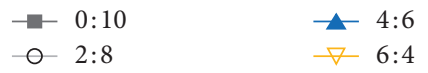

(b)

FiguRE 8: Water stability test results of recycled asphalt mixtures. (a) Residual stability. (b) Freeze-thaw splitting test strength ratio. 


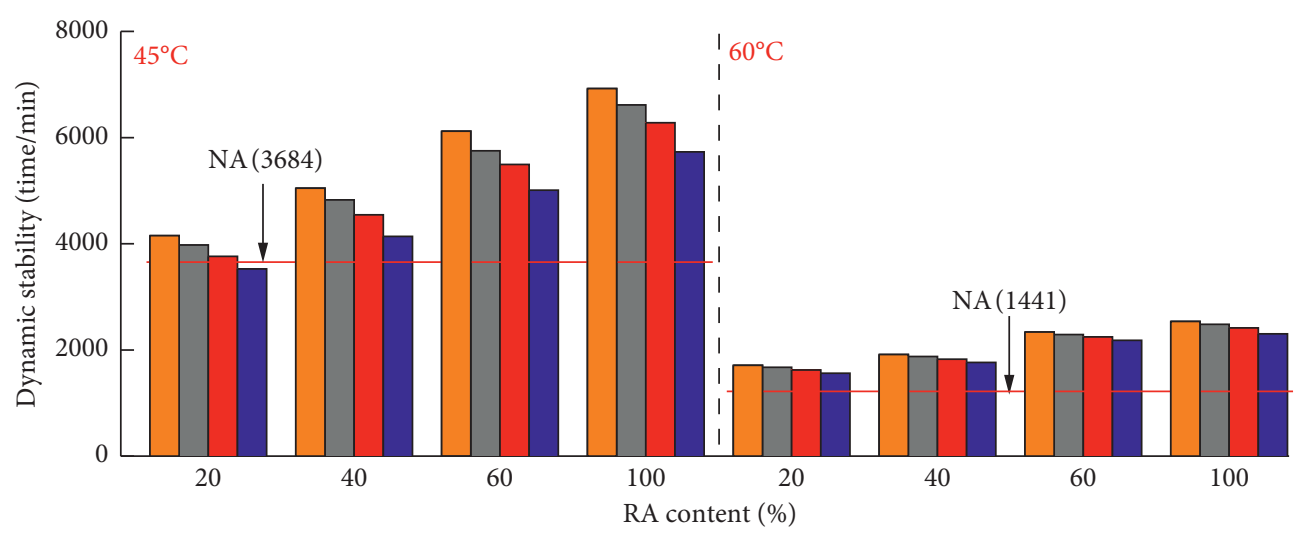

Proportion of RBA:RCA

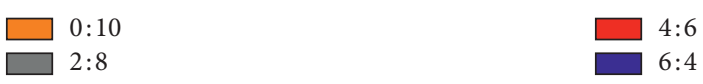

Figure 9: Dynamic stability test results of recycled asphalt mixtures.

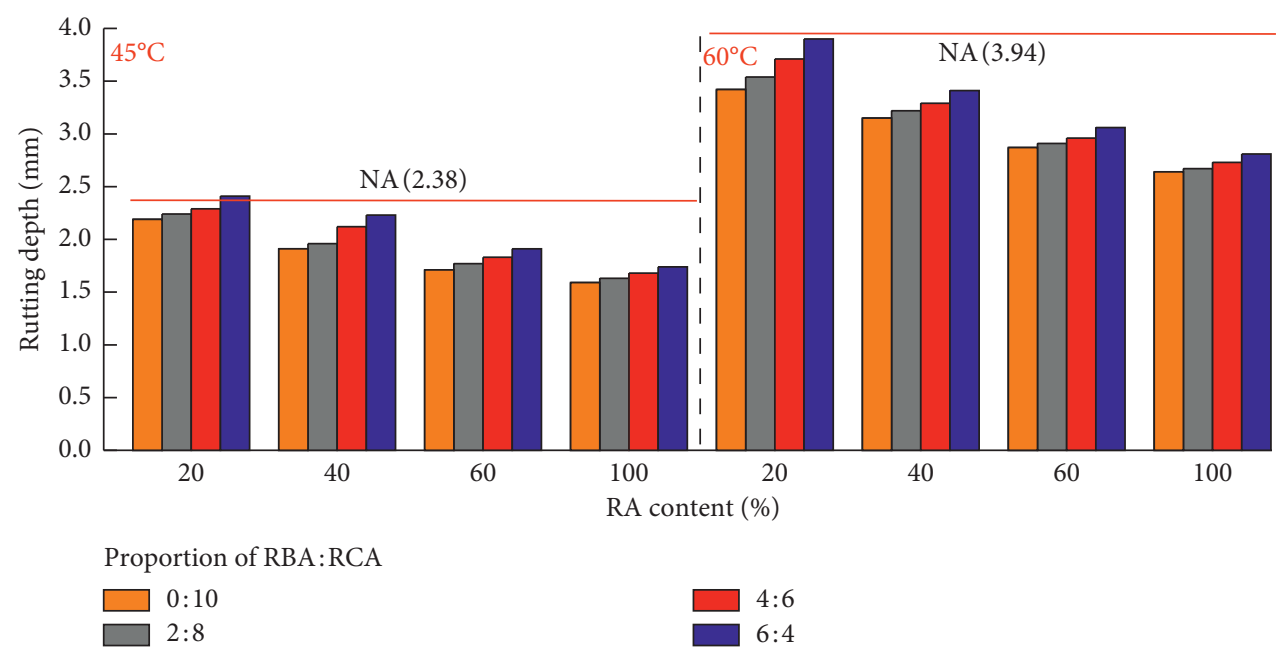

FIgURE 10: Rutting depth of recycled asphalt mixtures.

bricks to concrete should be controlled within $6: 4$ and $4: 6$ in cases of $25 \%$ and $50 \%$ RA content, and less than $2: 8$ if RA content exceeds $75 \%$.

In general, with the increase of RA content and proportion of bricks to concrete, the water stability indexes all decrease. The porosity of RAM gets larger as RA content increases, and water molecules can move into internal part of the specimen more easily. Simultaneously, as the composition of RA is complex, the adhesion strengths between different recycled materials and asphalt are diverse, which directly affects the bonding effect. Large voidage and the shortage of adhesion make the water stability performance of RAM poorer.

3.4. High-Temperature Stability. Figure 9 shows the test results of high-temperature stability under two temperatures $\left(45^{\circ} \mathrm{C}\right.$ and $\left.60^{\circ} \mathrm{C}\right)$. When the RA content increased from $0 \%$ to $100 \%$, the dynamic stability all increased regardless of proportions of bricks to concrete. As the RA surface was rougher than that of NA with more edges, corners, and more coarse aggregates, it was conducive to the formation of an embedded structure. The design gradation of RA by Bailey method was close to the median value, ensuring that the RAM was compacted densely. For pure RCA mixtures, the dynamic stabilities were 1.88 and 1.75 times that of NA mixtures, respectively, in two temperatures. When the adding RA content was $100 \%$ and proportion of bricks to concrete was $6: 4$, the ratio of dynamic stability between RAM and NA mixtures still remained in 1.56 and 1.59. In the condition of fixed RA content, the dynamic stability decreases with the increasing proportion of bricks to concrete. With the increase of content of bricks to a certain value, the water absorption ability of RAM got higher, but the amount of adsorbed asphalt decreased, making the internal cohesion of RAM weakened.

Figure 10 reveals that the change law of rutting depth was consistent in two temperatures. In contrast to the dynamic stability, with the RA content increased from $0 \%$ to $100 \%$, more coarse aggregates existed in RAM, and the embedded 
skeleton structure was formed easily with a better rutting resistance ability; thus, the rutting depths all decreased. During the rutting board forming process, with the low strength of RBA, it was easy to be crushed into fine aggregates to fill the skeleton between particles, making the structure more compacted and not easy to form rutting. Overall, for its porous characteristics, RBA can absorb surplus asphalt and improve the adhesion between asphalt and aggregates.

\section{Conclusions}

As a promising material in pavement base, RAM play an increasingly important role in recycling solid wastes and reducing engineering cost. Laboratory tests were performed to investigate the effect of recycled bricks and concrete on the property of RAM. The conclusions that can be drawn from the previous findings and observations are listed below:

(1) According to the design of Bailey method, the final proportion of each grading aggregate is $33.3 \%, 24 \%$, $12.3 \%, 26 \%$, and $4.4 \%$, close to the recommended median curve; it is helpful to make tested aggregates form a dense skeleton structure.

(2) Through Marshall Test, it seems that the stability, density, and asphalt saturation decrease with the increase of RA content, but oppositely for the flow value and voidage.

(3) From the scanning electron microscopy, the adhesion interface morphology between three aggregates and asphalt, as well as their adhesion property, is significantly different; natural aggregates show the best bonding with asphalt, the recycled concretes the second, and the recycled bricks the worst.

(4) China's technical specification (JTG F40-2004) and the test results of the road performances of RAM were taken as reference. The RA content and the corresponding proportion of bricks to concrete are recommended as follows to fill the requirement of pavement base in expressway: when the RA contents are $25 \%$ and $50 \%$, the corresponding proportion of bricks to concrete should be controlled within $6: 4$ and $4: 6$, and it should be less than $2: 8$ if RA contents increase to more than $75 \%$.

\section{Data Availability}

The data used to support the findings of this study are included within the article.

\section{Conflicts of Interest}

The authors declare that there are no conflicts of interest regarding the publication of this paper.

\section{Acknowledgments}

The authors gratefully acknowledge the National Natural Science Foundation of China $(51878078,51911530215$, and
51478054), Training Program for High-Level Technical Personnel in Transportation Industry (2018-025), Excellent Youth Foundation of Natural Science Foundation of Hunan Province (2018JJ1026), and Key Project of Education Department of Hunan Province (17A008). This work was also supported by the Key Project of Open Research Fund of National Engineering Laboratory of Highway Maintenance Technology (kfj150103) and Postgraduate Scientific Research Innovation Project of Hunan Province (CX20190644).

\section{References}

[1] L. Zheng, H. Wu, H. Zhang et al., "Characterizing the generation and flows of construction and demolition waste in China," Construction and Building Materials, vol. 136, pp. 405-413, 2017.

[2] R. Jin, B. Li, T. Zhou, D. Wanatowski, and P. Piroozfar, "An empirical study of perceptions towards construction and demolition waste recycling and reuse in China," Resources, Conservation and Recycling, vol. 126, pp. 86-98, 2017.

[3] P. Ghisellini, X. Ji, G. Liu, and S. Ulgiati, "Evaluating the transition towards cleaner production in the construction and demolition sector of China: a review," Journal of Cleaner Production, vol. 195, pp. 418-434, 2018.

[4] M. N. Soutsos, K. Tang, and S. G. Millard, "Concrete building blocks made with recycled demolition aggregate," Construction and Building Materials, vol. 25, no. 2, pp. 726-735, 2011.

[5] B. Huang, X. Wang, H. Kua, Y. Geng, R. Bleischwitz, and J. Ren, "Construction and demolition waste management in China through the 3R principle," Resources, Conservation and Recycling, vol. 129, pp. 36-44, 2018.

[6] B. Kourmpanis, A. Papadopoulos, K. Moustakas, M. Stylianou, K. J. Haralambous, and M. Loizidou, "Preliminary study for the management of construction and demolition waste," Waste Management \& Research, vol. 26, no. 3, pp. 267-275, 2008.

[7] A. Ossa, J. L. García, and E. Botero, "Use of recycled construction and demolition waste (cdw) aggregates: a sustainable alternative for the pavement construction industry," Journal of Cleaner Production, vol. 135, pp. 379-386, 2016.

[8] R. Cardoso, R. V. Silva, J. D. Brito, and R. Dhir, "Use of recycled aggregates from construction and demolition waste in geotechnical applications: a literature review," Waste Management, vol. 49, pp. 131-145, 2016.

[9] T. Park, "Application of construction and building debris as base and subbase materials in rigid pavement," Journal of Transportation Engineering, vol. 129, no. 5, pp. 558-563, 2003.

[10] C. Sangiorgi, C. Lantieri, and G. Dondi, "Construction and demolition waste recycling: an application for road construction," International Journal of Pavement Engineering, vol. 16, no. 6, pp. 530-537, 2014.

[11] K. Sobhan and R. J. Krize, "Fatigue behavior of fiber-reinforced recycled aggregate base course," Journal of Materials in Civil Engineering, vol. 11, no. 2, pp. 124-130, 1999.

[12] I. D. Rey, J. Ayuso, A. Barbudo, A. P. Galvín, F. Agrela, and J. D. Brito, "Feasibility study of cement-treated $0-8 \mathrm{~mm}$ recycled aggregates from construction and demolition waste as road base layer," Road Materials and Pavement Design, vol. 17, no. 3, pp. 678-692, 2015.

[13] J. Zhang, L. Ding, F. Li, and J. Peng, "Recycled aggregates from construction and demolition wastes as alternative filling materials for highway subgrades in China," Journal of Cleaner Production, vol. 255, Article ID 120223, 2020. 
[14] I. Pérez, A. R. Pasandín, and L. Medina, "Hot mix asphalt using c \& d waste as coarse aggregates," Materials \& Design (1980-2015), vol. 36, pp. 840-846, 2012.

[15] A. R. Pasandín and I. Pérez, "Laboratory evaluation of hotmix asphalt containing construction and demolition waste," Construction and Building Materials, vol. 43, pp. 497-505, 2013.

[16] M. Arabani, F. M. Nejad, and A. R. Azarhoosh, "Laboratory evaluation of recycled waste concrete into asphalt mixtures," International Journal of Pavement Engineering, vol. 14, no. 6, pp. 531-539, 2013.

[17] S. Wu, J. Zhong, J. Zhu, and D. Wang, "Influence of demolition waste used as recycled aggregate on performance of asphalt mixture," Road Materials and Pavement Design, vol. 14, no. 3, pp. 679-688, 2013.

[18] C. Medina, W. Zhu, T. Howind, M. I. S. D. Rojas, and M. Frías, "Influence of mixed recycled aggregate on the physical-mechanical properties of recycled concrete," Journal of Cleaner Production, vol. 68, pp. 216-225, 2014.

[19] M. Arshad and M. F. Ahmed, "Potential use of reclaimed asphalt pavement and recycled concrete aggregate in base/ subbase layers of flexible pavements," Construction and Building Materials, vol. 151, pp. 83-97, 2017.

[20] Y. J. Jiang and L. F. Fan, "An experimental investigation of optimal asphalt-aggregate ratio for different compaction methods," Construction and Building Materials, vol. 91, pp. 111-115, 2015.

[21] P. Ahmedzade and B. Sengoz, "Evaluation of steel slag coarse aggregate in hot mix asphalt concrete," Journal of Hazard Materials, vol. 165, no. 1-3, pp. 300-305, 2009.

[22] M. C. Rubio, F. Moreno, A. Belmonte, and A. Menéndez, "Reuse of waste material from decorative quartz solid surfacing in the manufacture of hot bituminous mixes," Construction and Building Materials, vol. 24, no. 4, pp. 610-618, 2010.

[23] Y. Huang, R. N. Bird, and O. Heidrich, "A review of the use of recycled solid waste materials in asphalt pavements," $R e$ sources, Conservation and Recycling, vol. 52, pp. 58-73, 2007.

[24] K. Hu, Y. Chen, F. Naz, C. Zeng, and S. Cao, "Separation studies of concrete and brick from construction and demolition waste," Waste Management, vol. 85, pp. 396-404, 2019.

[25] E. Mulder, T. P. R. D. Jong, and L. Feenstra, "Closed cycle construction: an integrated process for the separation and reuse of c \& d waste," Waste Management, vol. 27, no. 10, pp. 1408-1415, 2007.

[26] C. Ulsen, H. Kahn, G. Hawlitschek, E. A. Masini, and S. C. Angulo, "Separability studies of construction and demolition waste recycled sand," Waste Management, vol. 33, no. 3, pp. 656-662, 2013.

[27] H. Qasrawi and I. Asi, "Effect of bitumen grade on hot asphalt mixes properties prepared using recycled coarse concrete aggregate," Construction and Building Materials, vol. 121, pp. 18-24, 2016.

[28] P. Jitsangiam, P. Chindaprasirt, and H. Nikraz, "An evaluation of the suitability of superpave and marshall asphalt mix designs as they relate to Thailand's climatic conditions," Construction and Building Materials, vol. 40, pp. 961-970, 2013.

[29] M. M. Rafi, A. Qadir, and S. H. Siddiqui, "Experimental testing of hot mix asphalt mixture made of recycled aggregates," Waste Management \& Research, vol. 29, no. 12, pp. 1316-1326, 2011.

[30] J. Peng, J. Zhang, J. Li, Y. Yao, and A. Zhang, "Modeling humidity and stress-dependent subgrade soils in flexible pavements," Computers and Geotechnics, vol. 120, Article ID 103413, 2020.

[31] J. Zhang, J. Peng, W. Liu, and W. Lu, "Predicting resilient modulus of fine-grained subgrade soils considering relative compaction and matric suction," Road Materials and Pavement Design, pp. 1-13, 2019.

[32] Y. Hou, X. Ji, J. Li, and X. Li, "Adhesion between asphalt and recycled concrete aggregate and its impact on the properties of asphalt mixture," Materials, vol. 11, no. 12, p. 2528, 2018.

[33] S. Paranavithana and A. Mohajerani, "Effects of recycled concrete aggregates on properties of asphalt concrete," Resources, Conservation and Recycling, vol. 48, no. 1, pp. 1-12, 2006.

[34] K. Jankovic, D. Nikolic, and D. Bojovic, "Concrete paving blocks and flags made with crushed brick as aggregate," Construction and Building Materials, vol. 28, no. 1, pp. 659663, 2012.

[35] C. S. Poon and D. Chan, "Feasible use of recycled concrete aggregates and crushed clay brick as unbound road sub-base," Construction and Building Materials, vol. 20, no. 8, pp. 578585, 2006.

[36] L. Zeng, X. Yao, J. Zhang, Q.-F. Gao, J. Chen, and Y. Gui, "Ponded infiltration and spatial-temporal prediction of the water content of silty mudstone," Bulletin of Engineering Geology and the Environment, 2020.

[37] Y. D. Wong, D. D. Sun, and D. Lai, "Value-added utilisation of recycled concrete in hot-mix asphalt," Waste Management, vol. 27, no. 2, pp. 294-301, 2007.

[38] A. Mueller, A. Schnell, and K. Ruebner, "The manufacture of lightweight aggregates from recycled masonry rubble," Construction and Building Materials, vol. 98, pp. 376-387, 2015. 